Iranian Journal of Forensic Medicine - ISSN 2383-0034

\title{
Investigation Complaints from Neurosurgeons Referred to the Office of the Forensic Medicine Committees of Tehran
}

\author{
Hamidreza Daneshparvar ${ }^{1}$, Seyyed Amir Hossein Mahdavi² \\ 1. Associate Professor of Legal Medicine Research Center, Legal Medicine Organization, Tehran, Iran \\ 2. Assistant Professor of Legal Medicine Research Center, Legal Medicine Organization, Tehran, Iran
}

\begin{abstract}
Article Info
Received: $\quad 11$ Jan 2017

Accepted: $\quad 16$ Nov 2017

Published Online:03 Dec 2017

DOI: $10.30699 /$ epub.sjfm.23.3.215

Abstract

Background: One of the most important professional problems for doctors is the dissatisfaction and complaints of patients to the jurisdictions and the consequences in their personal and professional life. These medical errors may occur in different parts of the health care system. This study aimed to investigate failure cases of neurological surgeons referred to the Department of Forensic Medicine Commission in Tehran during a five-year period 2010-2014.
\end{abstract}

Original Article

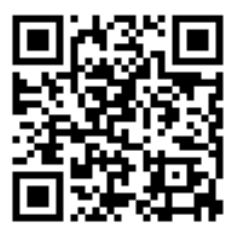

Materials and Methods: In this descriptive cross-sectional study, all cases which referred to Forensic Medicine Commission from 2010 to 2014, were evaluated for demographic and specific variables.

Findings: The total number of complaints from medical failure from the beginning of 2010 to the end of 2014 is 11370 , of which 340 cases (3\%) were related to the failure of the medical specialty of neurosurgery. The range of ages was between 1 and 92 years old. Complainant consists of 217 males and 123 females. Neurosurgeons consist of 338 males and 2 females in this 5 year period. The most frequent cause of complaints was the death of the patient after surgery. 127 therapeutic interventions in University centers, 62 therapeutic interventions in governmental non-university centers and 151 therapeutic interventions in private centers were done. Out of 340 complaints cases of neurological surgeons, 255 cases $(75 \%)$ of neurosurgeons were acquitted and $85(25 \%)$ were condemned.

Conclusion: The total number of complaints from neurological surgeons during the years 2010-2014 is increasing. There is a correlation between the frequency of failures of neurogenic surgeons with the sex of the neurosurgeon, and male surgeons have committed more failure than female surgeons, which can be attributed to the presence of a significant number of male neurological surgeons for female in this field as well as the fact that more patients refer to male neurosurgeons in the country.

Keywords: Medical Failure, Neurosurgery, Patient Complaints Organization, Tehran, Iran. Email: hardanesh@yahoo.com. Tel: 021-55619099

Copyright (C) 2017, Ir J Forensic Med. This is an open-access article distributed under the terms of the Creative Commons Attribution-noncommercial 4.0 International License which permits copy and redistribute the material just in noncommercial usages, provided the original work is properly cited.

How to Cite This Article:

Daneshparvar H, Mahdavi A. Investigation Complaints from Neurosurgeons Referred to the Office of the Forensic Medicine Committees of Tehran. Ir J Forensic Med. 2017; 23 (3):215-224 


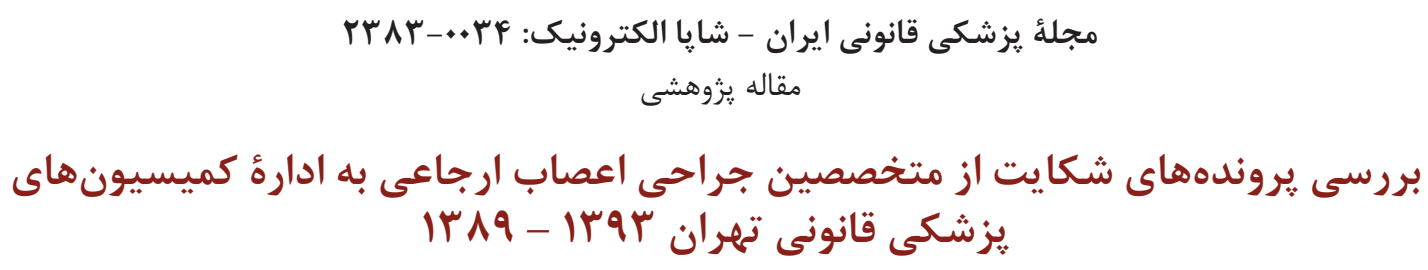

حميدرضا دانش يرور '"." سيد امير حسين مهدوى r

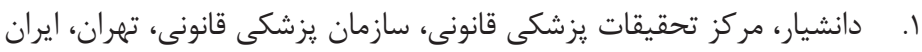

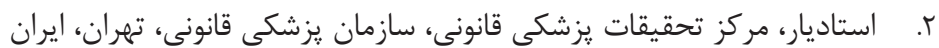

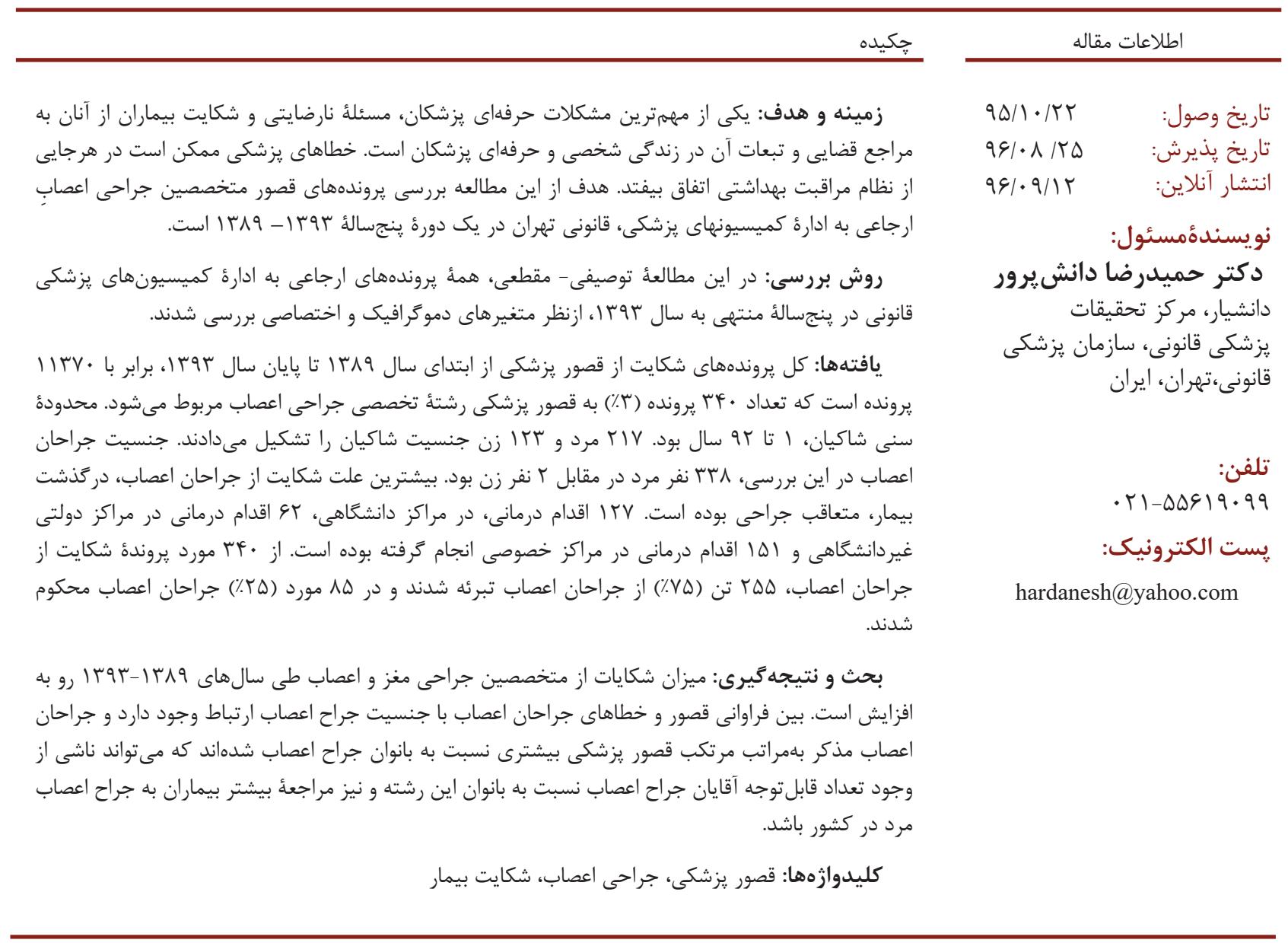


ماده هو ب قانون مجازات اسلامى در همين خصوص مقرر

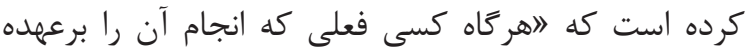

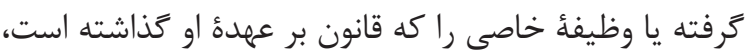

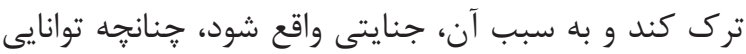

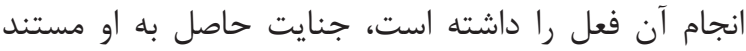

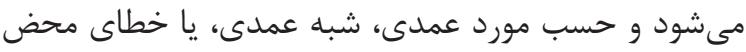
است، مانند اينكه يزشك يا يُ يرستار وظيفه

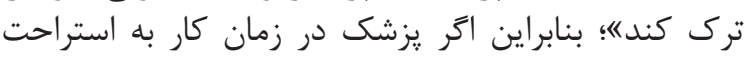

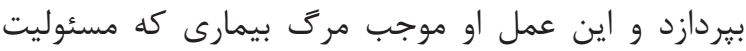

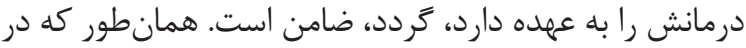

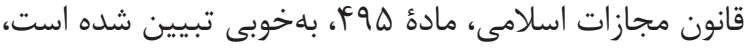

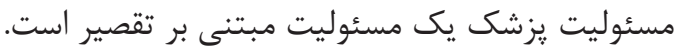

نظر به اينكه در رشتهٔ تخصصى جراحى مغز و اعصاب

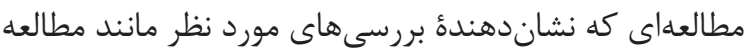

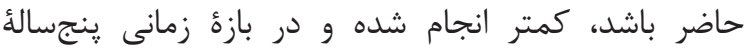

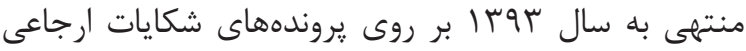

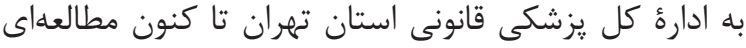

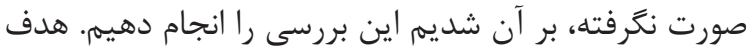

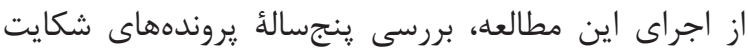

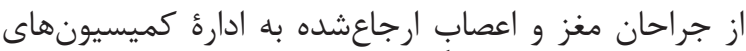

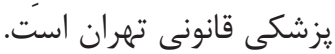

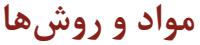

اين يروهش يك مطالعهُ توصيفى - مقطعى است. جمعيت

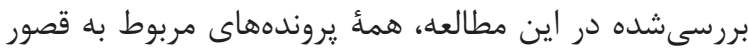

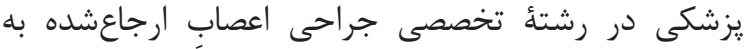

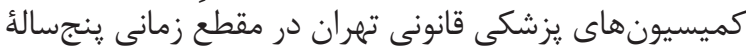

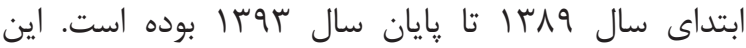

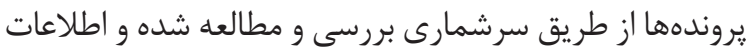

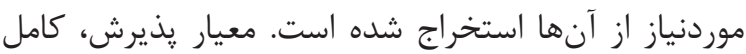

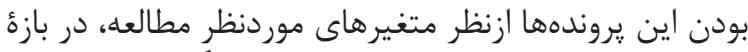

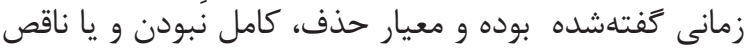

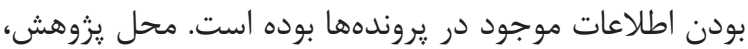

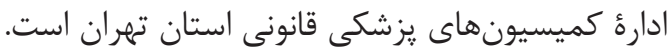

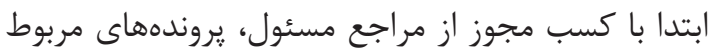

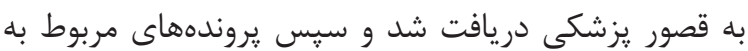

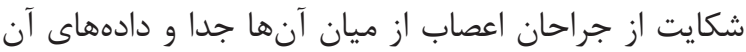

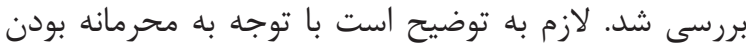

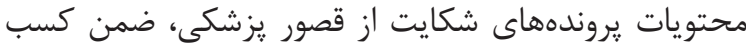

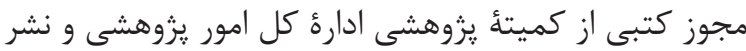

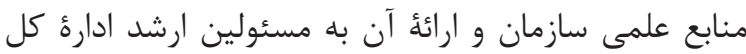

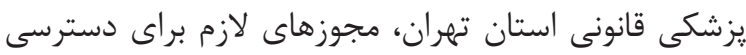

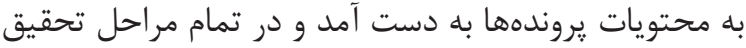
و انتشار نتايج تحقيق، از آشكار شدن اطنات دراعات نمات محرمانه تحفئ
جراحان مغز و اعصاب به دليل انجام جراحى هاى يِيجيده،

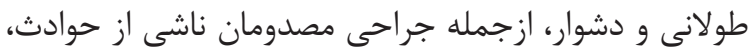

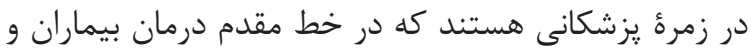

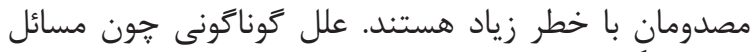

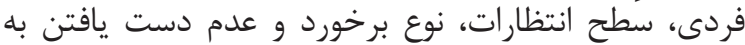

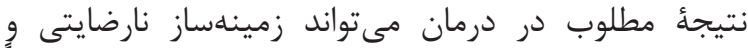

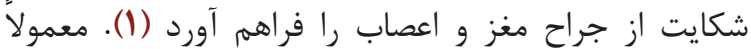

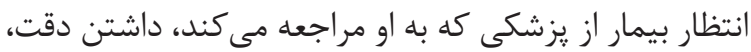

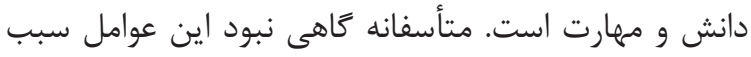

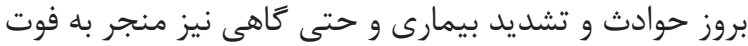

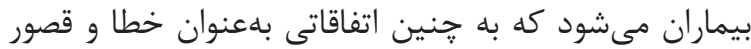
يزشكى نكر يسته مى شيود.

شكايت از قصور يزشكى در ايران نيز همانند ديكر نقاط

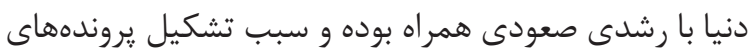

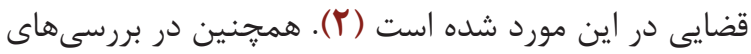

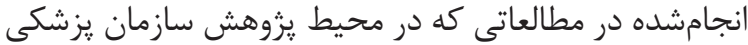

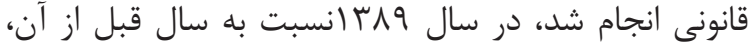

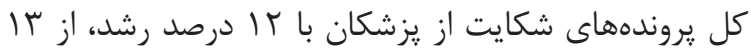

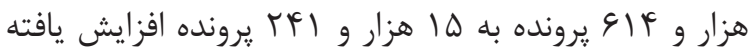

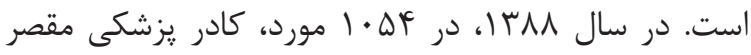

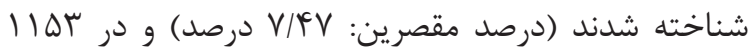

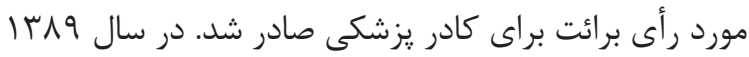

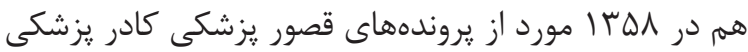

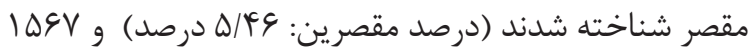

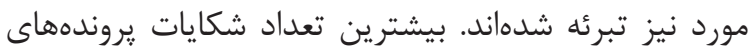

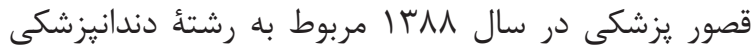

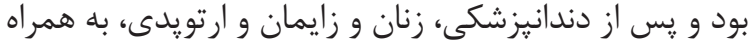

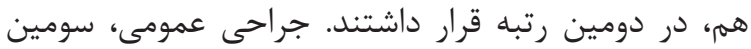

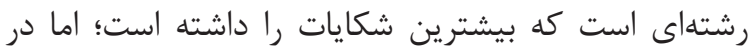

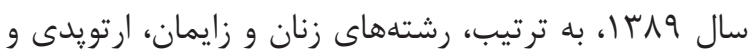

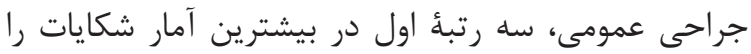
داشتند (T) (T).

ازلحاظ حقوقى اين يرسش مطرح است كه خه هـ هنكام

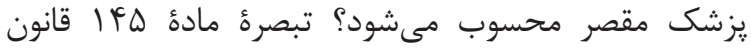

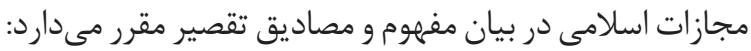

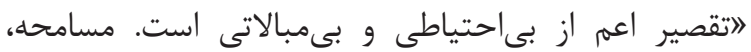

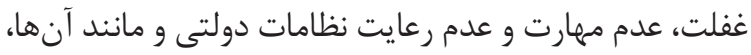

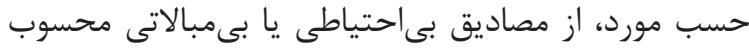

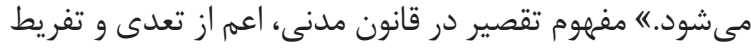

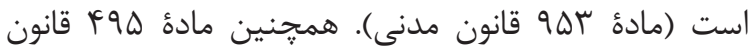

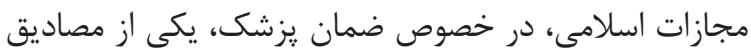

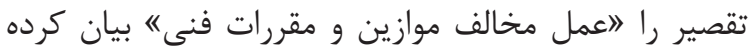

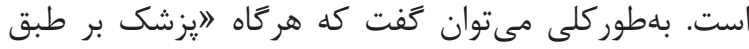

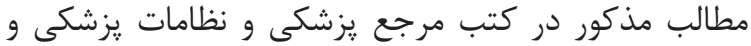

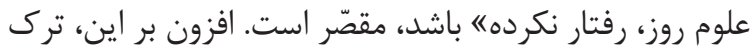

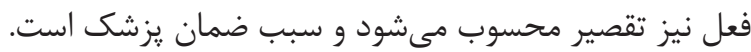


كافتهها

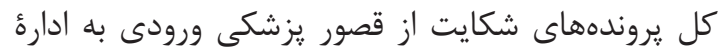

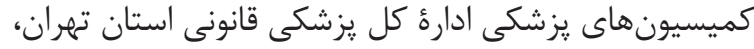

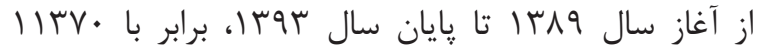

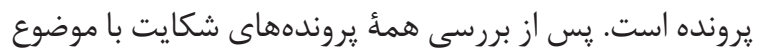

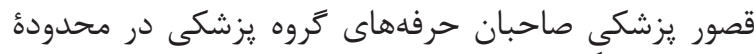

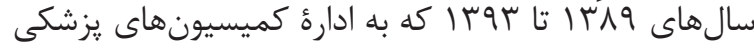

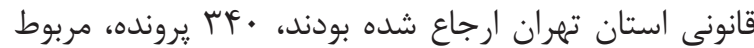

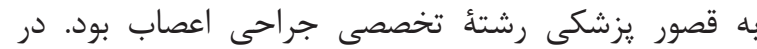

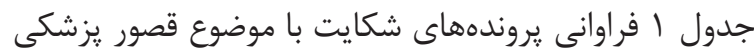

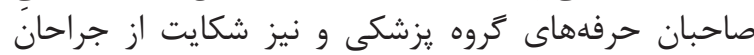

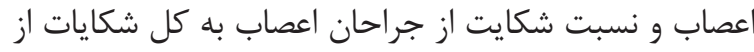

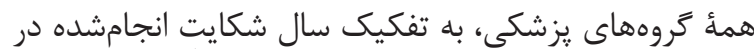

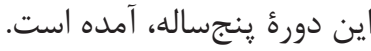

اشخاص حقيقى و حقوقى يرهيز شد.

يس از جمعآورى نمونهها كه يروندههاى شكايت از قصور

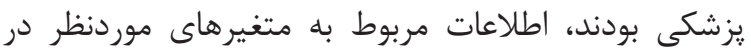

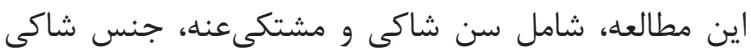

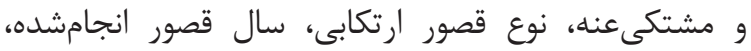

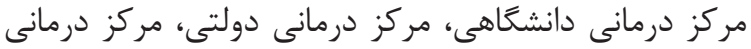

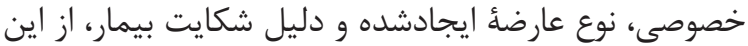

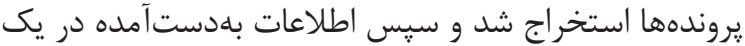

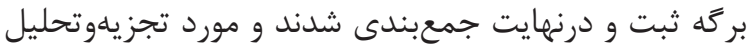
قرار كرفتند.

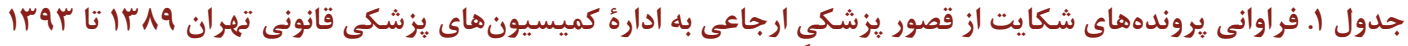

\begin{tabular}{|c|c|c|c|c|c|c|}
\hline جمع & Irar & Irat & $|r a|$ & irq. & 1\%^9 & 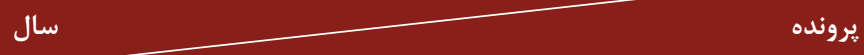 \\
\hline $11 \% \mathrm{re}$ & TQIA & TFY & TFFF & $r \cdot 9 \Delta$ & $19 \pi \mathrm{r}$ & كل بروندههاى شكايت از قصور بزشكى ارجاعى به كميسيون بزشكى استان تهران \\
\hline ry. & Ar & VV & 99 & \& & $\Delta T$ & كل يروندههاى قصور يزشكى جراحى اعصاب ارجاعى به كميسيون يزشكى استان \\
\hline$\%$ & $\%$ & $\%$ & $\% / \mathrm{T}$ & $\%$ & $\% / \mathrm{r}$ & 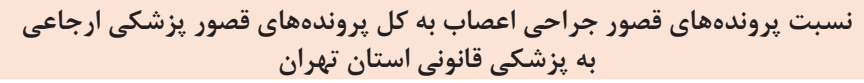 \\
\hline
\end{tabular}

در اين دورة گِنجساله ذكر شده است.

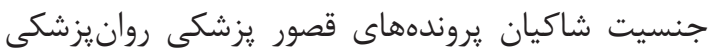

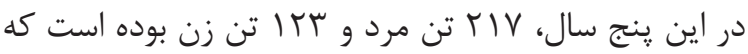

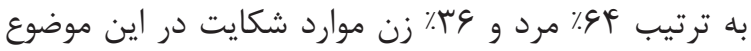

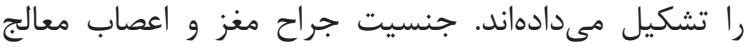

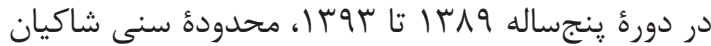

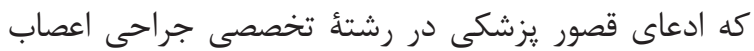

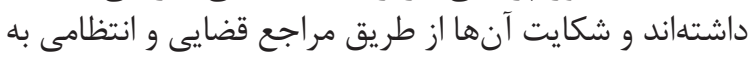

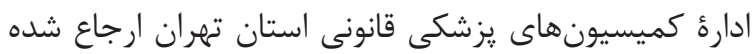

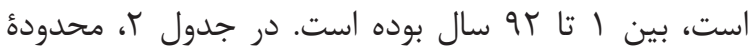
سنى اين شاكيان و متوسط سن آنان، به تفكيك سال شكايت دول

جدول r. سن شاكيان از قصور احتمالى جراحان مغز و اعصاب به تفكيك سال شكايت از قصور احتمالى جراحان مغز و اعصاب

\begin{tabular}{|c|c|c|}
\hline محدودة سنى شاكيان از قصور احتمالى جراحان & متوسط سن شاكيان از قصور احتمالى جراحان & سال شكايت از قصور احتمالى جراحان مغز و \\
\hline r Vال Vال & fr & 1 1r人9 \\
\hline q تا ז9 سال & $\forall \wedge$ & $1 \% q$. \\
\hline ا تا اج سال & FV & $\mid r q 1$ \\
\hline 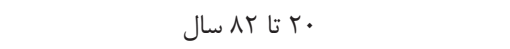 & fr & Irar \\
\hline זا تا \&1 سال & rq & rצו \\
\hline
\end{tabular}




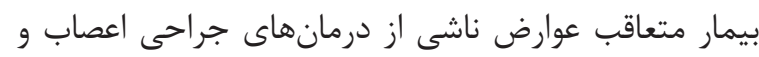

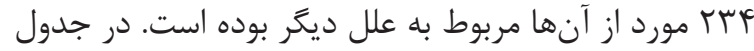

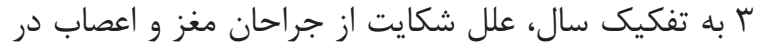
اين دورهٔ هنجساله ذكر شده است

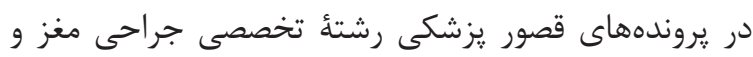

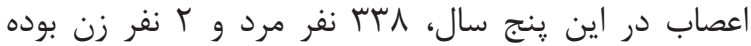

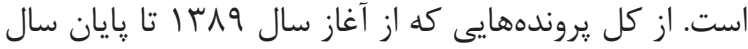

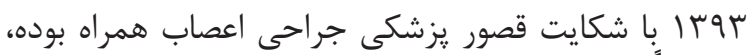

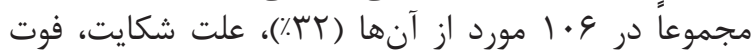

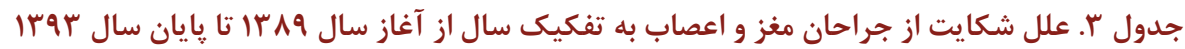

\begin{tabular}{|c|c|c|c|c|c|c|}
\hline 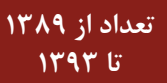 & تعداد در سال & تعداد در سال & تعداد در سال & 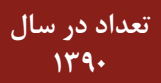 & تعداد در سال & علل شكايت بيمار از جراح مغز و اعصاب معالج \\
\hline ra & 9 & 4 & $\wedge$ & V & $\Delta$ & نتيجهُ نامطلوب كرفتن از درمان ديسكوياتى مهرى \\
\hline IV & r & $\Delta$ & r & r & r & نتيجة نامطلوب كرفتن از درمان ديسكوياتى \\
\hline 19 & r & f & r & r & $r$ & نتيجهُ نامطلوب كرفتن از درمان جراحى تومور \\
\hline ra & 4 & 4 & r & 4 & r & نتيجئ نامطلوب كرفتن از درمان تومور مغزى \\
\hline V & 1 & $r$ & 1 & $r$ & 1 & نتيجهُ نامطلوب كرفتن از درمان جراحى اختلالات \\
\hline$r$. & V & $\Delta$ & k & $r$ & $r$ & نتيجة نامطلوب ترفتن از درمان جراحى ضربه مهاو \\
\hline 19 & f & r & r & r & $r$ & نتيجئ نامطلوب كرفتن از درمان جراحى شكستكى فرات \\
\hline TT & r & $\Delta$ & 4 & r & r & نتيجهُ نامطلوب ترفتن از درمان لغزش مهرههاى \\
\hline 19 & $\Delta$ & r & 1 & $\&$ & f & نتيجئ نامطلوب كرفتن از درمان جراحى تنغى \\
\hline$\Delta V$ & 19 & 10 & $\wedge$ & $\wedge$ & 1. & نتيجة نامطلوب ترفتن از ديكر درمانهاى جراحى \\
\hline $1 \cdot 9$ & re & r & ro & 19 & 10 & در اثر اقدامات درمانى جراحى مغز و اعصاب \\
\hline
\end{tabular}

ارجاعى، به ترتيب شيوع، عبارتاند از: عفونت، خونريزى، بوري،

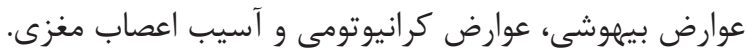
همجنين در بررسى هاى بهعمل آمده، علل شكايت پيس از

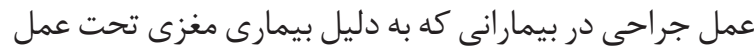

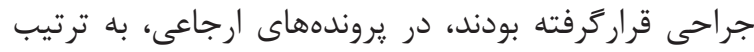

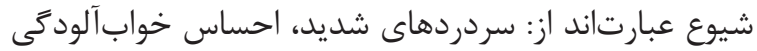

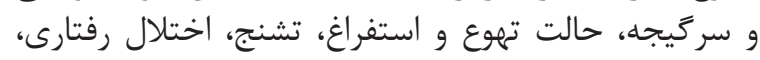

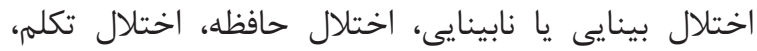

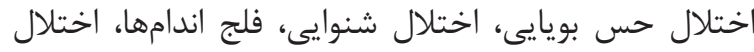

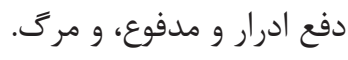

شكايت از اقدامات درمانى انجامشده توسط متخصصين

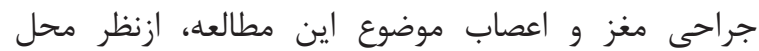

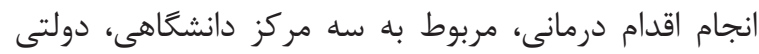

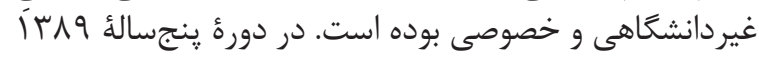

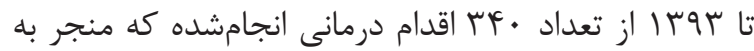

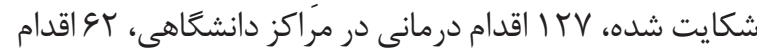
درمانى در مراكز دولتى غيردانشخاهى و الها ا اقدام درمانى در درانئ
در بررسىهاى بلهعمل آمده، علل شكايات يس از عمل

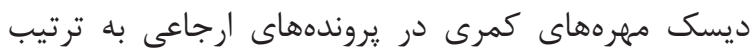
شيوع، عبارتاند ازي مثري

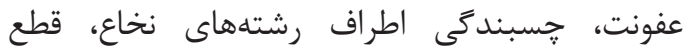

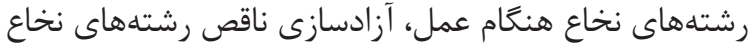

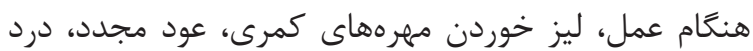

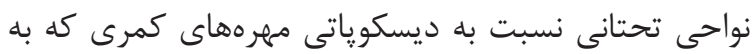

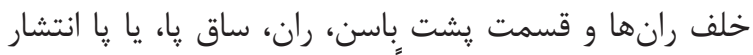

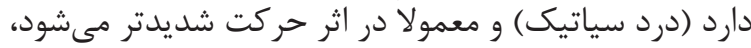
كرفتتى عضلات، تشديد درد براثر كشيد

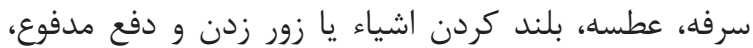

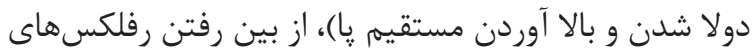

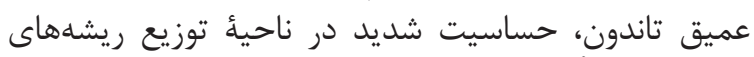

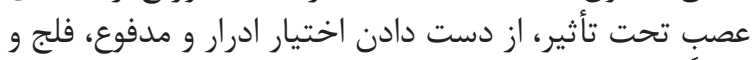
تحليلً رفتن و ضعف عضل تاتير، دات دست دات

بعلاوه، در بررسىهاى بهعمل آمده، علل شكايتها يس از

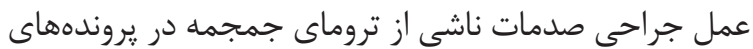




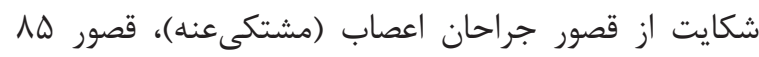

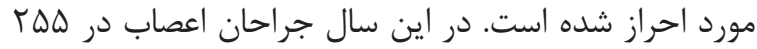

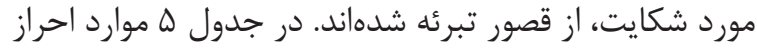

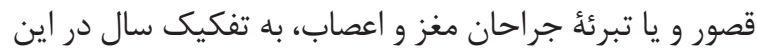
دورة ينجساله آمده است.

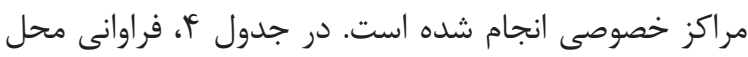

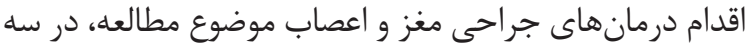

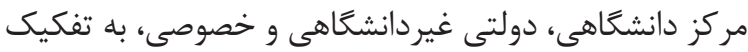

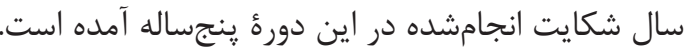
در دورة ينجسالة

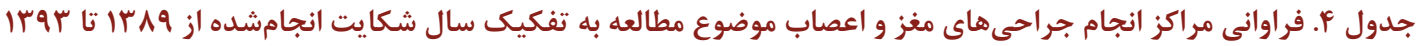

\begin{tabular}{|c|c|c|c|c|c|c|}
\hline 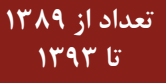 & تعداد در سال & تعداد در سال & تعداد در سال & تعداد در سال & تعداد در سال & محل انجام جراحى مغز و اعصاب موضوع مطالعه \\
\hline$(\% r V) \mid r V$ & rA & r. & tr & re & re & مراكز دانشعاهى \\
\hline$(\%) \Lambda) \& 4$ & 19 & 19 & $\wedge$ & ז & 4 & مراكز دولتى غيردانشعاهى \\
\hline$(\%+\Delta)|Q|$ & ro & il & r & TF & r. & مراكز خصوصى \\
\hline
\end{tabular}

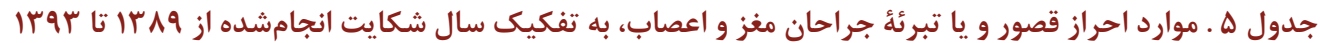

\begin{tabular}{|c|c|c|c|c|c|c|}
\hline 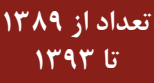 & تعداد در سال & تعداد در سال & تعداد در سال & تعداد در سال & 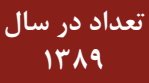 & بررسى ازنظر قصور يا تبرئهُ جراح اعصاب \\
\hline ry. & Ar & VV & 99 & ז & dr & شكايت از جراح مغز و اعصاب \\
\hline$(\%\ulcorner\Delta) \wedge \Delta$ & 19 & rq & Ir & 11 & Ir & موارد احراز قصور جراح مغز و اعصاب \\
\hline$(\% \vee \Delta) r \Delta \Delta$ & \& & \&A & $\Delta r$ & Dr & ५q & موارد تبرئه از قصور جراح مغز و اعصاب \\
\hline
\end{tabular}

س-درنتيجهُ اين اقدامات، بيمار متحمل آسيب روانى يا

جسمى شده باشد (F). (F)

بهرحال بايد بدانيم كه يزشكان مسئول خطاهاى خود

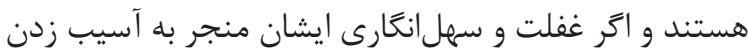

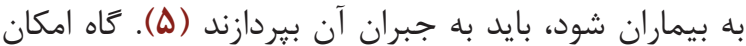

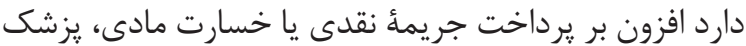

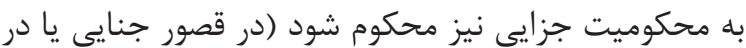

موارد قصور منجر به فوت بيمار) (IF)

مطابق آمار در كشور آمريكا، شكايت از زيزشكان از

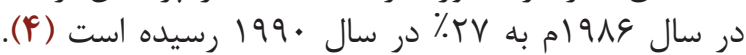
مطالعهُ ديخرى كه در اين كشور انجام شده است، نشان الهان

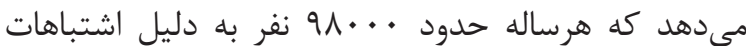

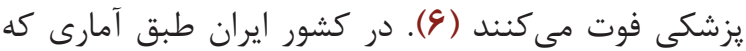

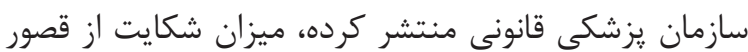

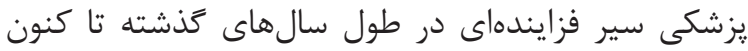
داشته است (V)

البته اگر زيزشك، درمان يا جراحى را مطابق نظامهاى

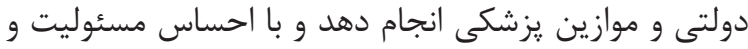

بحث

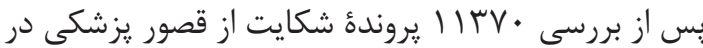

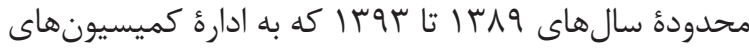

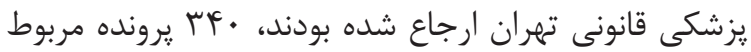

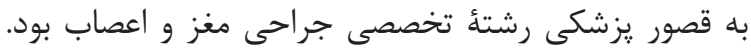

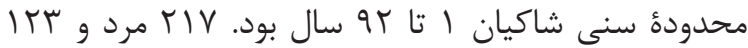

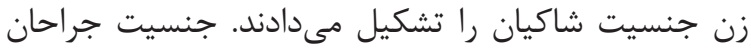

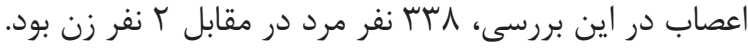

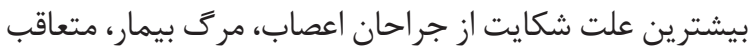

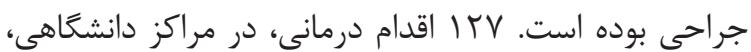

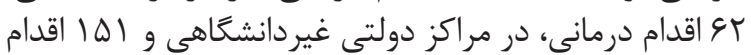

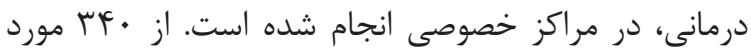

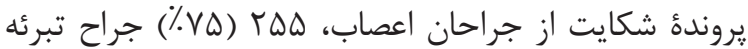

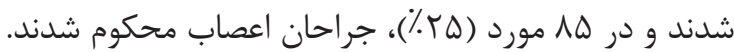
در رشتأ يزشكى قصور وقتى رخ مى دهد كه سه شرط زير

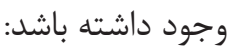
|-فرد بايد بيمار زيزشك باشد؛ يعنى يزشك مسؤوليت

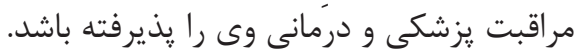
r-عمل يزشك مطابق با استانداردهاى يزشكى نباشد. 


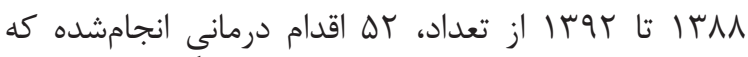

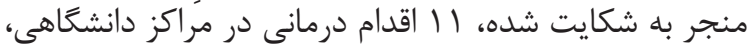

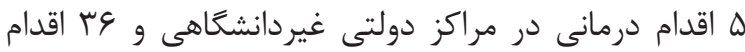

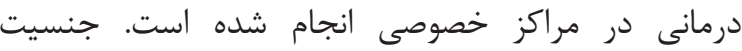

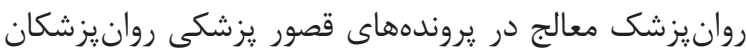

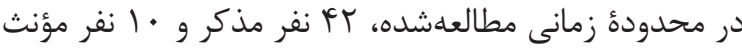

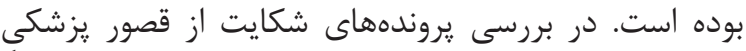

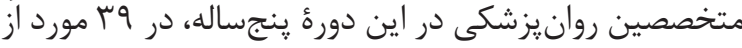

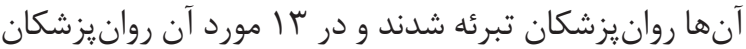

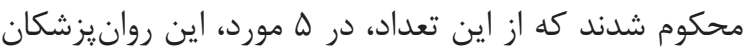

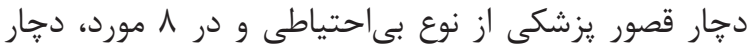

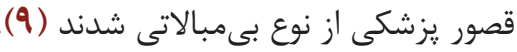

مقايسُٔ متغيرهاى اين مطالعه و مطالعأه حاضر نشان از

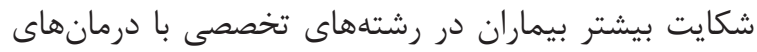

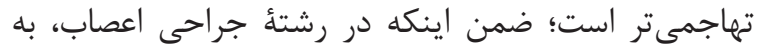

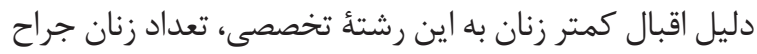

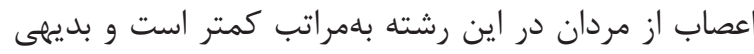

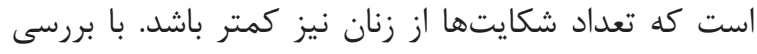

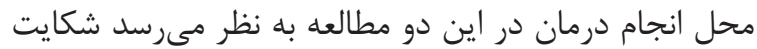

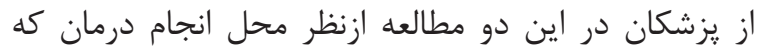

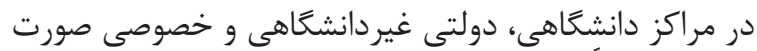

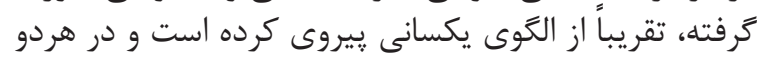

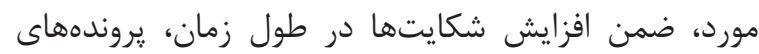

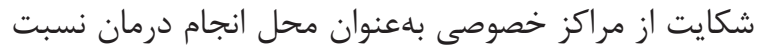

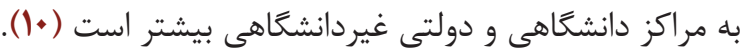
براى مسئوليت يزشكى وجود سه عنصر فعل مجرمانه يا

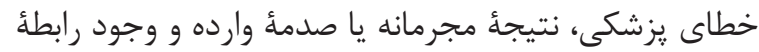

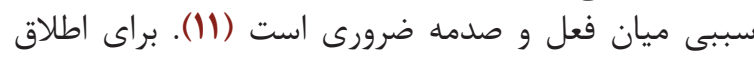
لفظ اقصور"، فردى كه مرتكب قصور مى فى فود، بايد وظيفه يا

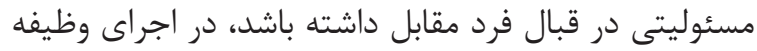

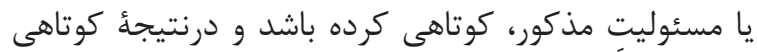

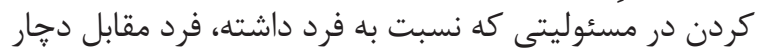

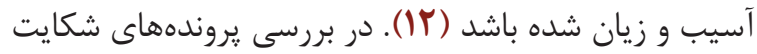

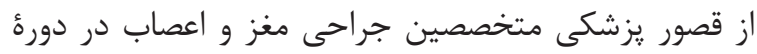

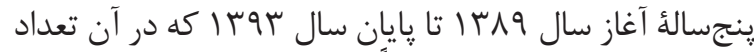

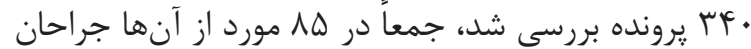

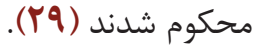

عدم تشخيص (Misdiagnosis) بيمارى در تمامى موارد

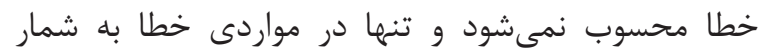
مى آيد كه فرد از تمام روشهاى دهى تشخيصى استفاده نكرد

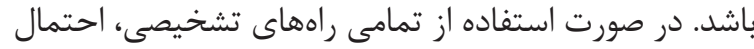

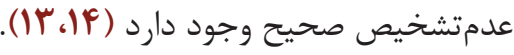

در مواردى كه صاحبان حرف يزشكى بهواسطة بى احتياطى

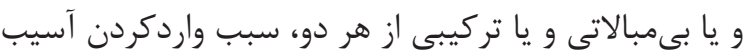

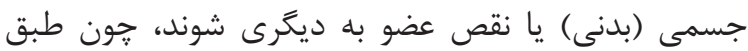

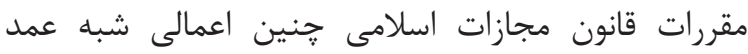

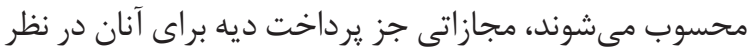

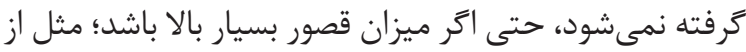

با حسٍن نيت و نيز با رعايت حال اقتصادى بيمار عمل كند،

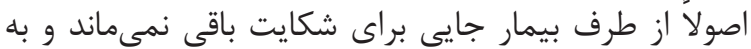

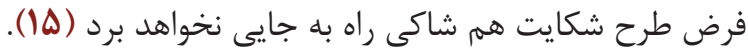
نتيجهاى كه از انجام يزوهش ييش رو رو حاصل شد، نشانگر

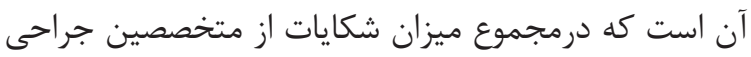

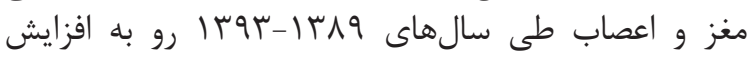

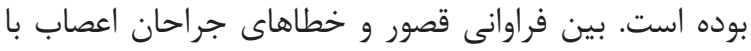

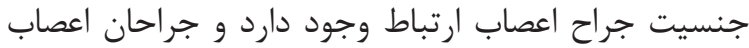

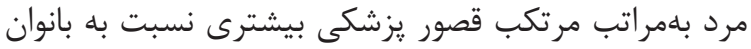

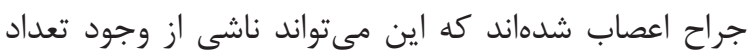

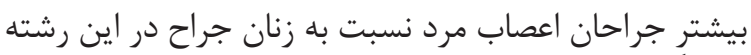

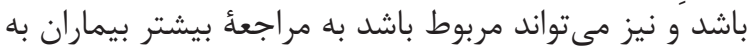

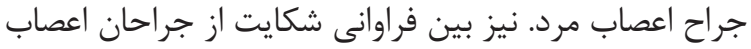

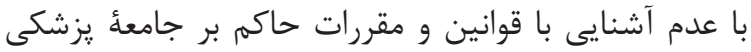

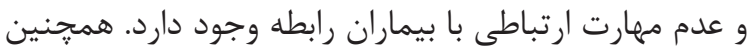

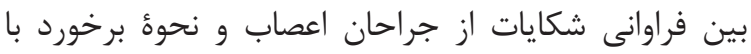

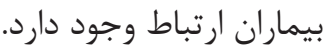

در بررسى :روندههاى شكايت از قصور يزشكى متخصصين

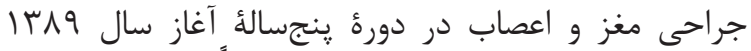

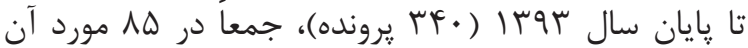

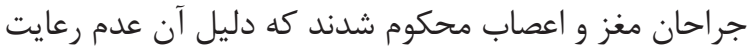

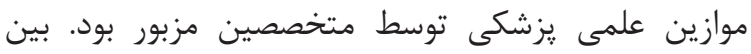

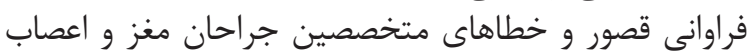

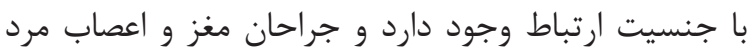

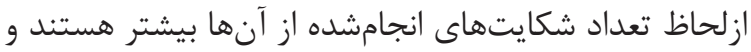

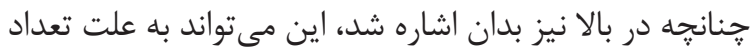

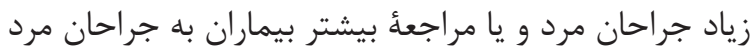
نسبت به جراحان زن بان مرد باش مراجد.

در مطالعهاى كه با موضوع قصور يزشكى در رشتهُ تخصصى

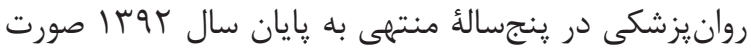

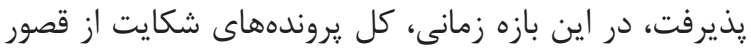

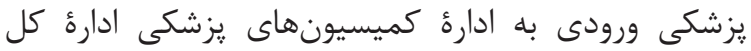

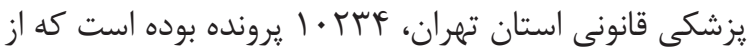

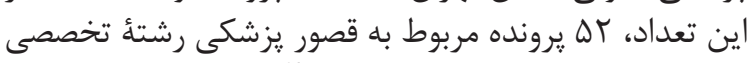

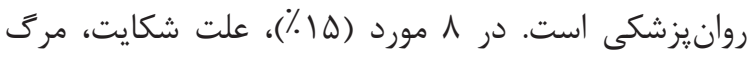

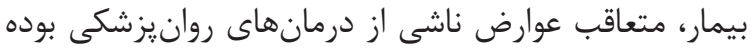

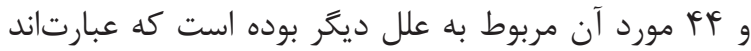

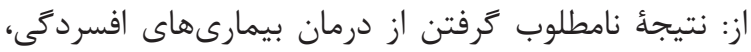

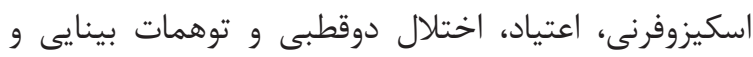

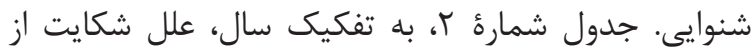

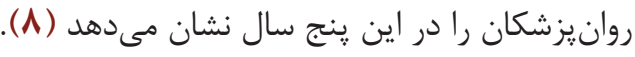

محدوده سنى اين شاكيان بين 19 تا 19 و و متوسط سن سن

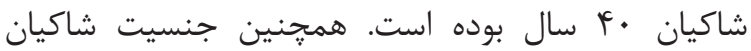

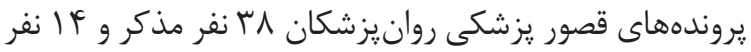

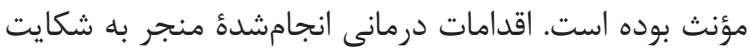

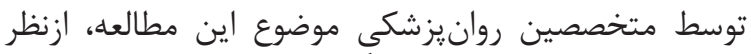

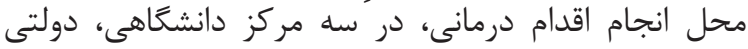

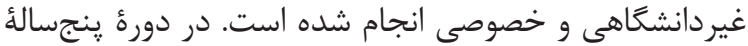


اين موضوع مسلم است كه آموزههاى قانونى و اطلاع

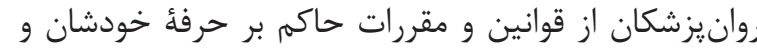

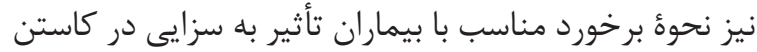

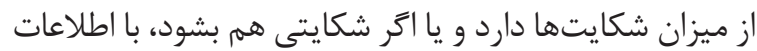

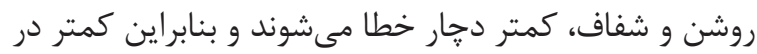
محاكم قضايى و انتظامى محكوم خواهند شند شئ

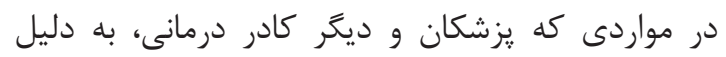

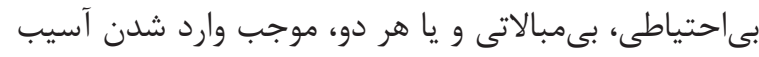

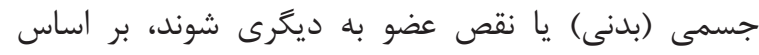

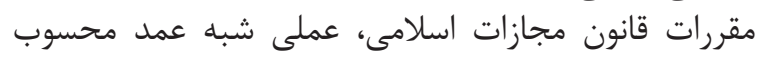

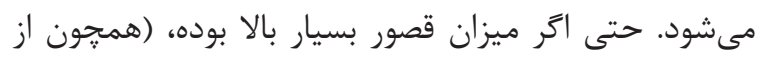

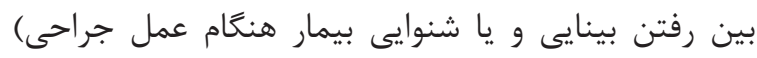

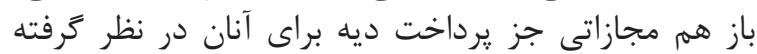

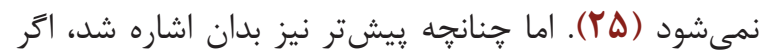

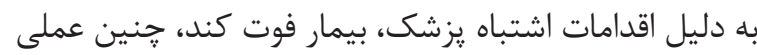

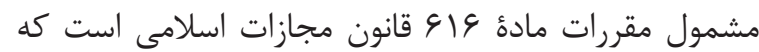

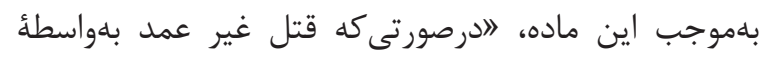

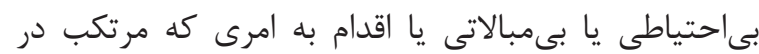

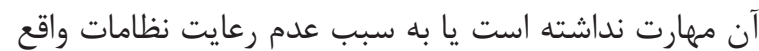

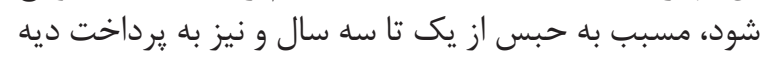

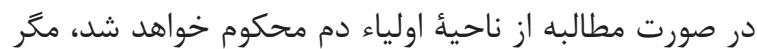

اينكه خطاى محض باشده (Y) (Y.TV).

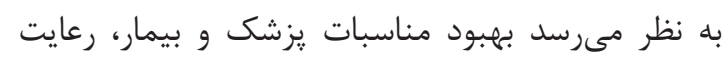

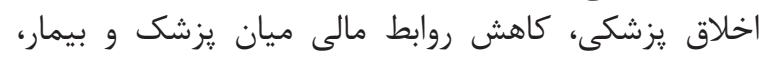

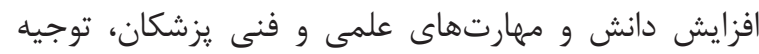

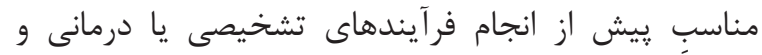

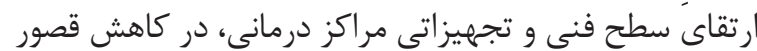

و شكايت تأثير بسزايى دارد (YN)

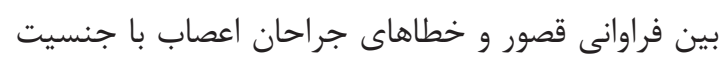

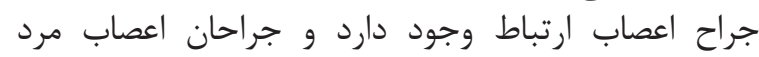

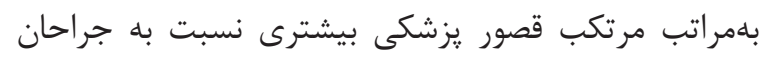

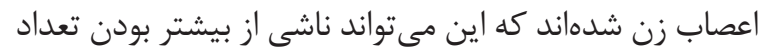

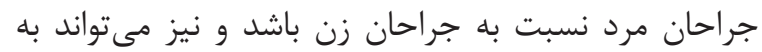

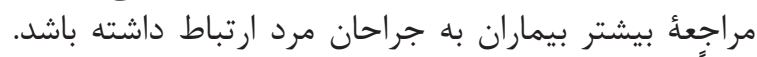

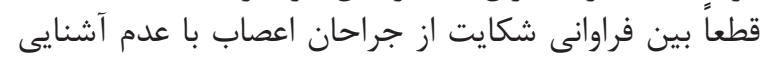

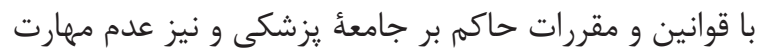

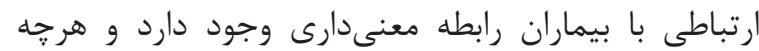

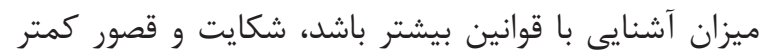

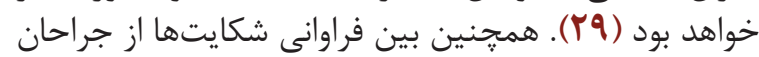

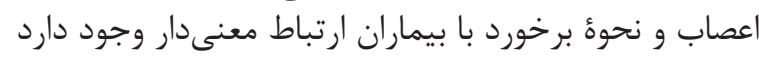

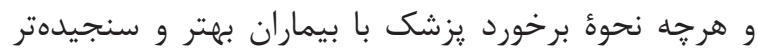

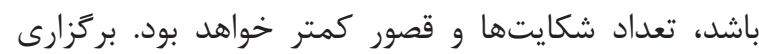

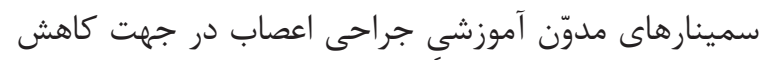

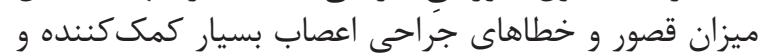

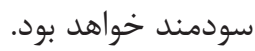

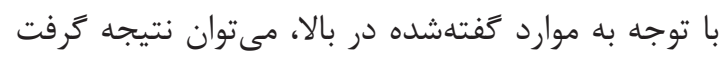

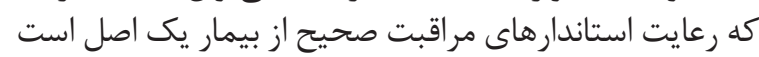

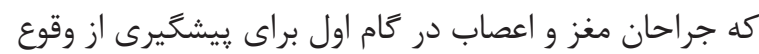

بين رفتن بينايى و يا شنوايى بيمار هنغام عمل جراحى؛ اما بـام

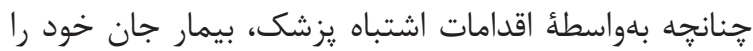

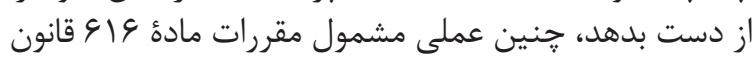

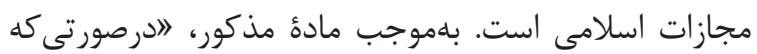

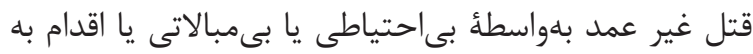

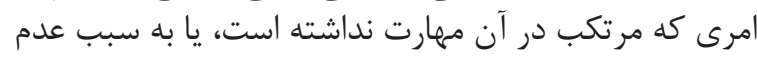

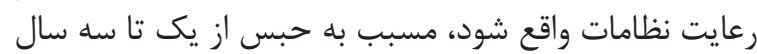

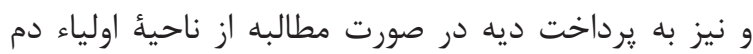

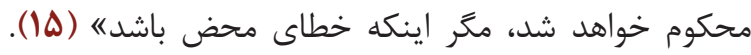

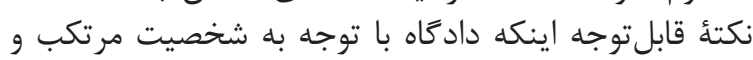

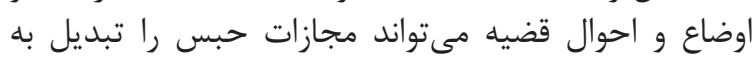
مجازات از نوع ديخرى همانند جزاى حبس حبس كند (1) (1).

\section{نتيجه}

اين واقعيت را نبايد ازنظر دور داشت كه يزشك هيجّاه

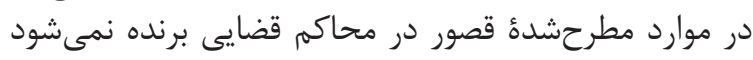
دان خوان (IV)

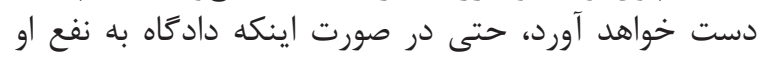

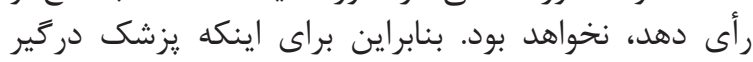

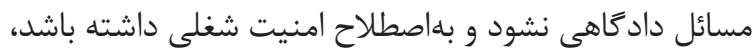

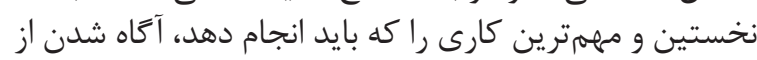

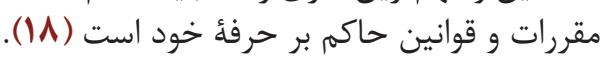

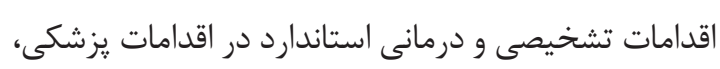

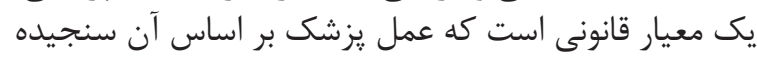

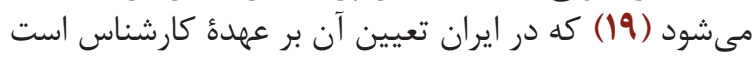

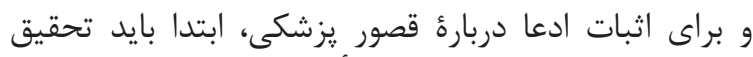

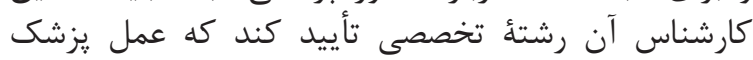

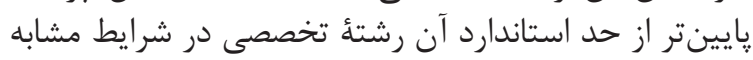

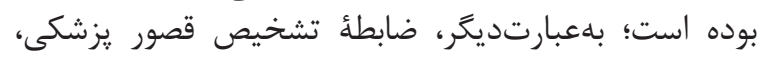

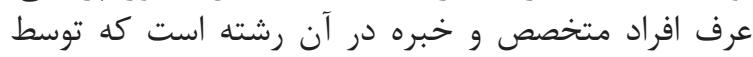

كارشناس آن رشته تشخيص داده ميره در آنود (•r).

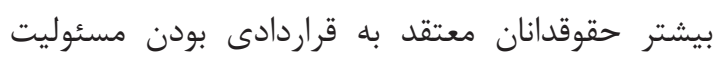

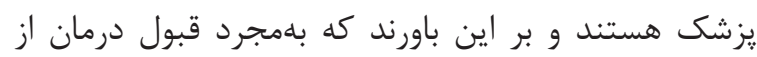

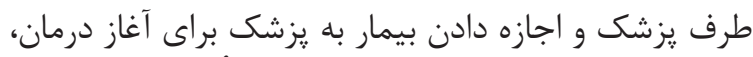

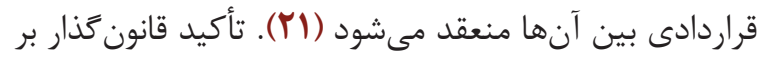

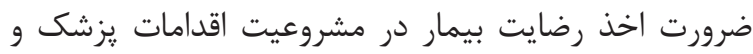

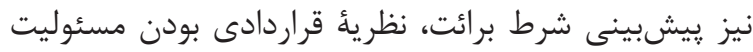

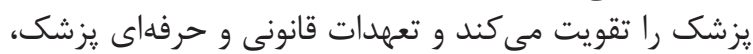

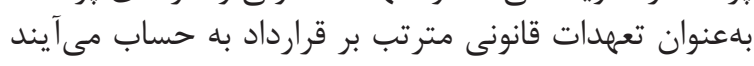

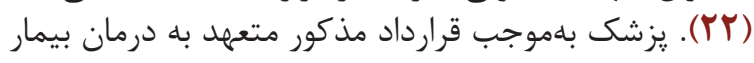

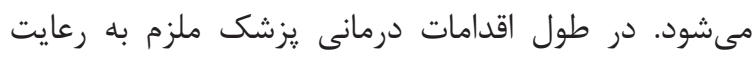

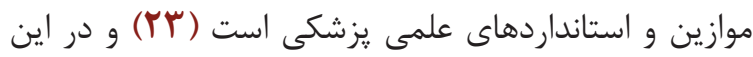

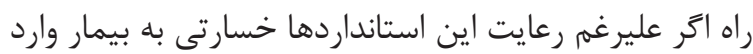

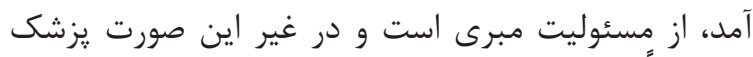

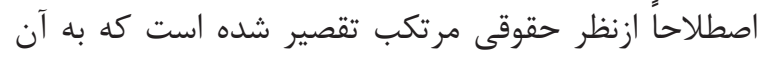

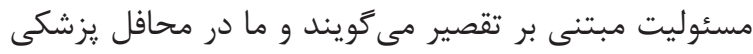
از آن به نام قصور ياد مى كنيم (YF). 


$$
\begin{aligned}
& \text { سياسگزارى } \\
& \text { نويسند }
\end{aligned}
$$

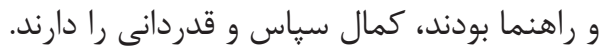

$$
\begin{aligned}
& \text { قصور يزشكى بايد بدان توجه كنند. اين استانداردها عبارتاند }
\end{aligned}
$$

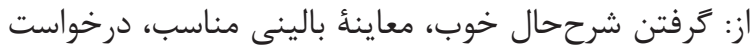

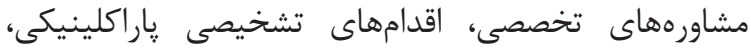

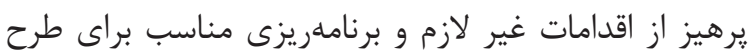

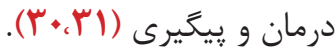

\section{References}

1. Tofighi H. Bargozideh Pezeshki Ghanooni, 4thed,Tehran: Legal Medicine Organization, 1997.

2. Saukko P., Knight B.: "Knight's forensic pathology" 4thed. New York. CRC press, Taylor and Francis Group, 2016

3. Polson C.J., Gee D. J., The Essentials of Forensic Medicine, 3rd.ed. Oxford :Pergamon Press London: Arnold:1985; 15-105Gannon K. Mortality associated with anaesthesia. A case review study. Anaesthesia. 1991;46(11):962-6.https://doi org/10.1111/j.1365-2044.1991.tb09859.x

4. Gannon K. Mortality associated with anaesthesia. A casereviewstudy.Anaesthesia. 1991 Nov;46(11):9626. https://doi.org/10.1111/j.1365-2044.1991.tb09859.x PMID:1750601

5. Holder AR. Medical errors. Hematology (Am Soc Hematol Educ Program). 2005;2005(1):503-6. https://doi.org/10.1182/asheducation-2005.1.503 PMID:16304427

6. Tofighi H, Shirzad J, Ghadipasha M. A survey on death due to medical malpractice during 1374 78. Ir J Forensic Med. 2003;8(27):5-8

7. Abbott RL, Weber P, Kelley B. Medical professional liability insurance and its relation to medical error and healthcare risk management for the practicing physician. Am J Ophthalmol. 2005;140(6):1106-11. https://doi.org/10.1016/j. ajo.2005.07.020

8. Amooei M, Soltani K, Kahani A, Najjari F, Roohi $\mathrm{M}$, , "A survey on medical malpractice referred to LMO during 1378", Iranian journal of forensic medicine, 2001;6(21):15-21

9. Sadr SS, Ghadyani MH, Bagher Zadeh AA. Assessment of records of complaints from medical malpractice in the field of orthopedic, in the coroner's Office of Forensic Medicine, province of Tehran, during 1988 to 2003. Ir J Forensic Med. 2007;13(2):78-86.

10. Medical Council of Islamic Republic of Iran's Law Islamic Penal Code of Iran (2013)
11. Islamic Penal Code of Iran (1392)

12. Akhlaghi M, Tofighi H,Samadi F, "Complaints from medical malpractice in the field of Gynecology referred to LMO during 1381 \& 1382 and methods of preventing them", Iranian journal of forensic medicine, 2004;10 - 34

13. Khavanin-zadeh M, Gholipour F. Complaints Related to Laparoscopic Surgery: a Survey of the Files Registered at Tehran Legal Medicine Center. International Journal of Hospital Research. 2013;2(4):215-8.

14. Parhizgar S, Fayaz A. Survey of complaints against ophthalmologists referred to legal medicine organization during 2000-2003. 2005.

15. Irden's Dental Database, E-Newsletter, Iranian Dental Association

16. Rafi zadeh tabaei M, Hajmanoochehri R, Nassaji zavareh M, "A survey on General physicians malpractice referred to Tehran Legal Medicine Organization(2003-2006)", Irn J Forensic Med,2007;13(3);147-51

17. Sadr SSh, Ghadyani M, Bagherzadeh A, "Assessment of records of complaints from medical malpractice in the field of orthopedic referred to LMO during 1377-82", Iranian journal of forensic medicine, 2007;13(2):78-86

18. www.lmo.ir

19. Heiner T, Barzó T, Orv Hetil. Topical issues of medical malpractices. 2014 Sep 1;155(38):15101516. Hungarian

20. Echigo J. Nihon Geka Gakkai Zasshi. ,” Diseases and procedures apt to conflict with patients: an analysis of medical malpractice litigation cases". 2014 Jul;115(4):231-5.

21. Adibzadeh A, Ghadipasha M, Pooramiri A, Nakhaei N, Samadirad B, Bastani M. Investigation of Medical failure caused by death and disability referred to Medical Council of Iran's commissions during 2002 to 2006, Journal of Medical Law, 2012 Spr,20(6) 
22. Baker SR, Shah S, Ghosh S, Castro A. Radiology medical malpractice suits in gastrointestinal radiology: prevalence, causes, and outcomes. Emerg Radiol. 2015;22(2):141-5. https://doi. org/10.1007/s10140-014-1268-3

23. Huff D, Mackenzie D. Practice tips to reduce malpractice exposure. Journal of the Medical Association of Georgia. 2014;103(2):24-6.

24. Haghshenas MR, Vahidshahi K, Amiri A, Rezaee M, Rahmani N, Pourhossen M, et al. Study the frequency of malpractice lawsuits referred to forensic medicine department and medical council, Sari, 2006-2011. Journal of Mazandaran University of Medical Sciences. 2012;21(86):253-60.

25. Safdari R, Masouri N, Ghadyani M, Shokrizadeh Arani L, "The importance of creation of specific electronic information system in order to referred claim due to medical malpractice in Legal Medicine Organization", Irn J Forensic med.2005;11(38) $99-106$

26. Mahfoozi A, Taghadosi Nejad F, Abedi Khorasegani H, "A 6 years study on anesthesiologist's medical malpractice cases referred to Tehran medicolegal commission(1994-1999)", Irn J Forensic med. 2002; 8(26)4 -10

27. Echigo J.Nihon Geka Gakkai Zasshi. , "Diseases and procedures apt to conflict with patients: an analysis of medical malpractice litigation cases", 2014 Jul;115(4):231-5.

28. Navvabi N., Chamani G., Zareei M., Jalali P.," Referral patterns and medical failures in people with oral mucosal diseases before referring to Oral Diseases Clinic of Kerman Dental School" , Journal of Medical Council of Iran, Sep. 2009; 27(3):317-232

29. Berger VW. Conflicts of Interest, Selective Inertia, and Research Malpractice in Randomized Clinical Trials: An Unholy Trinity. Sci Eng Ethics. 2015;21(4):857-74. https://doi.org/10.1007/ s11948-014-9576-2

30. Mirakbari SM, Fathi M, Taghadosinejad F, Atri A. Malpractice Claims in Nasal Surgeries Referred to Forensic Medicine Service Tehran, Iran From 1996 through 2002: A preliminary study. Ir J Forencis Med. 2003; 9(3): 136 - 138

31. Farhadi Y., Golmakani M., Haghighi Z., Pirzadeh R., "Evaluation of the level and types of medical malpractice among physicians during the years 1365 to 1376 in Tehran", Quarterly Journal of Teb and Tazkieh, Winter 2004, Number 55, p. 21 26. 